\title{
Call for papers: NJL Special Issue on Prosody in the Nordic Languages
}

The second issue of Volume 38 (autumn 2015) of the Nordic Journal of Linguistics will be a special issue devoted to prosody in the Nordic languages. The special issue will be edited by Merle Horne and Mikael Roll.

The Nordic languages (the five Scandinavian languages plus Finnish, Greenlandic and Saami) are characterized by a wealth of features that make them a rich source of data for exploring a wide range of prosodic phenomena stretching from tone and intonation to voice quality, quantity, and rhythm. The modelling of the prosodic structure of the Nordic languages has been the focus of many researchers during the past decades and we are now in a position to be able to rigorously test these models in different kinds of empirical studies ranging from comparative studies of dialect prosody and typological investigations of prosodic features to experimental studies of prosody processing in the brain. The editors welcome contributions dealing with all aspects of Nordic prosody and the relation of Nordic prosody features to those of other languages.

Submissions for papers should follow the style sheet of $N J L$ available at http://assets.cambridge.org/NJL/NJL_ifc.pdf.

The deadline for submitted papers is 15 January 2015. Papers should be sent to either of the two guest editors:

Merle Horne

Linguistics

Center for Languages and Literature

Lund University

P.O. Box 201

S-221 01 Lund

Sweden

Merle.Horne@ling.lu.se

\author{
Mikael Roll \\ Linguistics \\ Center for Languages and Literature \\ Lund University \\ P.O. Box 201 \\ S-22100 Lund \\ Sweden \\ Mikael.Roll@ling.lu.se
}

The reviewing process will take place in the spring of 2015. The final version of all accepted manuscripts will be submitted to the publisher by 1 July 2015 . 